Brazilian Journal
of Chemical
Engineering

ISSN 0104-6632

Printed in Brazil

www.abeq.org.br/bjche

Vol. 33, No. 02, pp. 261 - 270, April - June, 2016

dx.doi.org/10.1590/0104-6632.20160332s20150146

\title{
NITROGEN SOURCES ON TPOMW VALORIZATION THROUGH SOLID STATE FERMENTATION PERFORMED BY Yarrowia lipolytica
}

\author{
V. R. O. Lopes ${ }^{1}$, M. A. Farias ${ }^{1}$, I. M. P. Belo ${ }^{2}$ and M. A. Z. Coelho ${ }^{1 *}$ \\ ${ }^{1}$ Escola de Química, Universidade Federal do Rio de Janeiro, Centro de Tecnologia, Bloco E, Lab 103, \\ CEP: 21941-909, Cidade Universitária, Rio de Janeiro - RJ, Brasil. \\ E-mail: alice@eq.ufrj.br \\ ${ }^{2}$ IBB-Centre of Biological Engineering, University of Minho, Campus de Gualtar, 4710-057, Braga, Portugal.
}

(Submitted: March 3, 2015 ; Revised: May 7, 2015 ; Accepted: June 1, 2015)

\begin{abstract}
This manuscript reports the valorization of two-phase olive mill waste (TPOMW) as raw material and carbon source for solid state fermentation using Yarrowia lipolytica as biocatalyst. Due to its chemical characteristics, a combination of different raw materials (TPOMW and wheat bran, WB) was evaluated and two distinct nitrogen sources were applied as supplementation for lipase production. A TPOMW/WB ratio of 1:1 and supplementation with ammonium sulfate was chosen as the best condition. The productivity in $24 \mathrm{~h}$ reached $7.8 \mathrm{U} / \mathrm{g}^{*} \mathrm{~h}$ and, after four days of process, only decreased about $35 \%$. Process $\mathrm{pH}$ ranged from 5.5 5.9 , remaining in an acid range. Thus, the successful use of TPOMW, a watery solid by-product with high content of lipids, as raw material for Yarrowia lipolytica growth and lipase production provided an environmental friendly alternative to valorize such waste.

Keywords: Yarrowia lipolytica; Solid state fermentation; TPOMW valorization; Nitrogen.
\end{abstract}

\section{INTRODUCTION}

The olive oil industry is characterized by its great environmental impact due to the production of a highly polluted wastewater and/or a solid residue, olive skin and stone (olive husk), depending on the extraction process. The two-phase centrifugation system for olive oil production, developed to drastically reduce the water consumption, produces olive oil plus a semi-solid residue, known as two-phase olive mill waste (TPOMW). The resulting solid waste corresponds to $800 \mathrm{~kg}$ per ton of processed olives, containing $2.5-3.5 \%$ of residual oil and about $60 \%$ of water (Darvishi, 2012). Thus, more research is needed on the development of new bioremediation technologies and strategies for olive mill wastes, as well as its valorization by microbial biotechnology.

Yarrowia lipolytica is a non-conventional yeast, which has been considered an industrial workhorse because of its ability to produce important metabolites, intense secretory activity and efficient system for genetic engineering transformation (Coelho et al., 2010). Strictly aerobic, this yeast is often isolated from environments containing hydrophobic substrates, leading to the efficient use of alkane, fatty acids and triglycerides. Moreover, Y. lipolytica grows as a mixture of budding yeasts and long hyphae depending on the environmental conditions, being a useful model for dimorphism studies (CervantesChávez and Ruiz-Herrera, 2007). Y. lipolytica is used

*To whom correspondence should be addressed 
now as a model organism for several academic studies, making this dimorphic yeast significant for biotechnological applications. Properties like intracellular accumulation of oil, secretion of large amounts of organic acids, high capacity for enzyme secretion and its acceptance as generally recognized as safe (GRAS) focus the interest on this yeast as a potential producer of basic commodities (Barth and Gaillardin, 1997; Papanikolaou and Aggelis, 2010).

Lipases (E.C. 3.1.1.3), defined as triacylglycerol acylhydrolases, are ubiquitous enzymes that can catalyze the hydrolysis of the ester bond of longchain fatty acids into fatty acids and glycerol and also the reverse reaction when in organic solvents with low-water content. Besides hydrolysis, lipases can catalyze a wide range of reactions including inter-esterification, alcoholysis, acidolysis, esterification and aminolysis (Bora et al., 2013). These are one of the most important classes of enzymes with industrial applications such as in fine chemistry, detergent, textile, and food additives (Fickers et al., 2011). Lipases are naturally produced by plants, animals and microorganisms; however, enzymes produced by microorganisms have received increasing attention. Microbial lipases present a great variety of catalytic activities, possible high yields, easy genetic manipulation, a regular supply due to the absence of seasonal fluctuations and the rapid microorganism growth rate (Hasan et al., 2006).

Lipases are one the most important biocatalysts secreted by $Y$. lipolytica. There are several papers reporting three extracellular lipases that present different substrate specificities, Lip2, Lip7, and Lip8 (Pignède et al., 2000; Fickers et al., 2011; Najjar et al., 2011). Among these, Lip2 attracts more attention because it is the main secreted extracellular lipase and presents high hydrolysis, transesterification and esterification activities (Yan et al., 2013). Lipase production is induced by fatty acids derived from fat breakdown, like oleic, elaidic and linoleic acids. Inductors of lipase secretion when used as carbon source were also reported in the literature (Najjar et al., 2011). Although it is well known that the production of lipolytic enzymes is modulated by carbon and nitrogen sources, there is a lack of information about the role of specific substrates in lipase synthesis (Almeida et al., 2012). Microbial lipases are usually produced in submerged fermentation processes. However, solid state fermentation (SSF) seems to be an interesting alternative to microbial enzyme production due to the possibility of using agro-industrial residues as the source of carbon and other nutrients, as well as support for microorganism growth (Rigo et al., 2010). Industrial enzymes have been successfully produced at the commercial level by SSF. Never- theless efforts to obtain higher production with lower costs have to be continued (Thomas et al., 2013).

The choice of nitrogen source, organic or inorganic, has proven to be an important parameter for the improvement of lipase production. Playing a different role in enzyme synthesis, organic sources can supply cells with growth factors and amino acids, while inorganic sources can be quickly used (Almeida et al., 2012). Ammonia for example can be used not only as nitrogen source, but also as $\mathrm{pH}$ regulator during the induction stage. The ammonium ion released into the fermentation broth has a deep impact on cell growth, expression and degradation of foreign protein (Yu et al., 2013). Yeast extract and hydrolyzed casein are usually great nitrogen sources for lipase stimulation (Fickers et al., 2004; Moftah et al., 2012; Veerabhadrappa et al., 2013). Turki et al. (2010) reported valuable production of extracellular lipases by the yeast Yarrowia lipolytica LgX64.81, using a defined medium supplemented with tryptone. According to the authors the lipase production was higher using the medium enriched with tryptone than that using a complex medium, commonly employed for yeast cell growth.

The agro-industrial wastes used in SSF can differ in many properties, like the chemical nature of the constituents and water retention capacity, affecting directly the microorganism growth. TPOMW is a watery solid by-product of the olive oil industry that may represent an environmental problem due to its highly polluting organic load (Lama-Muñoz et al., 2013). At the same time, it represents an inexpensive and unexploited source of nutrients, rich in lipids that can act as inducers and make this waste a great alternative for lipase production in SSF. Although the presence of aromatic compounds, such as tannins and polyphenols, and the low nitrogen content in TPOMW generally inhibit microorganism growth (Muktadirul et al., 2013; Reina et al., 2013), the combination with other wastes can reduce the concentration of phenolic compounds and counteract the lack of nitrogen, improving the production of biocatalysts (Salgado et al., 2013).

WB is one of the most popular agro-industrial residues and is well accepted for microbial production of important enzymes applying SSF. Since it is a byproduct of the milling of wheat into white flour, WB usually accounts for 14-19\% of the grains' weight (Maes and Delcour, 2002; Demir and Tari, 2014). This residue is also an inexpensive carbon source that has already been reported as a good inductor for lipase activity (Romdhane et al., 2010).

In this study, the effect of different solid state media for lipase production by Yarrowia lipolytica IMUFRJ 50862 was investigated. Two-phase olive 
mill waste (TPOMW) and wheat bran (WB) were used as raw material and carbon source and two distinct nitrogen sources were applied as supplementation. The best ratio between the two raw materials for lipase production was also tested.

\section{MATERIALS AND METHODS}

\section{Microorganism}

A wild-type strain of Yarrowia lipolytica (IMUFRJ 50682), isolated from an estuary of Guanabara Bay in Rio de Janeiro, Brazil (Haegler et al., 1981), was used in this work. The yeast was maintained and propagated in YPD medium containing (w/v): $1 \%$ yeast extract, $2 \%$ peptone and $2 \%$ glucose. For lipase production, cells previously grown for 72 hours under orbital agitation $\left(160 \mathrm{rpm}, 28^{\circ} \mathrm{C}\right)$ were inoculated in SSF medium.

\section{Raw Materials}

Two agro-industrial residues, TPOMW and WB, were tested as substrate. TPOMW was collected from olive oil mill industries in the northern region of Portugal. This residue usually has high moisture content, in this case $73 \%$, so it was necessary to dry it prior to the fermentations. After the required drying, the solid matrix was milled to a particle size lower than $2 \mathrm{~mm}$. WB, collected from industries in the area (Braga, Portugal), was also dried, despite its low moisture content, due to the necessity of moisture standardization.

\section{Solid State Fermentation}

The fermentation was carried out in $250 \mathrm{~mL}$ Erlenmeyer flasks with $10 \mathrm{~g}$ of dry solid substrate with different ratios of the two residues. For lipase production using a mixture of raw materials, solutions of urea and ammonium sulfate were tested as nitrogen supplementation; they were also used to adjust the fermentation moisture level to 53\% (wet basis). Solutions and substrates were sterilized separately at $121{ }^{\circ} \mathrm{C}$, for $15 \mathrm{~min}$. The sterilized solid substrate was inoculated with $1 \mathrm{~mL}\left(10^{8}\right.$ cells $)$ of cell suspension and the necessary volume of nitrogen solution was added. After mixing, the fermentation flasks were incubated at $28^{\circ} \mathrm{C}$ for 96 hours.

\section{Crude Lipase Extraction}

The crude lipase was extracted with a solution composed of $1 \% \mathrm{NaCl}$ and $0.5 \%$ Triton X-100 at $4{ }^{\circ} \mathrm{C}$ in a solid/liquid ratio of 1:5. After 2 hours of agita- tion in a rotary shaker $\left(200 \mathrm{rpm}, 28{ }^{\circ} \mathrm{C}\right)$, the raw extract was obtained by pressing the mixture and subsequent filtration through Whatman No. 1 filter paper.

\section{Lipase Assay}

Extracellular lipase was measured by a colorimetric method using p-nitrophenyl-laurate (pNPL) as substrate. The pNPL was prior dissolved in dimethyl sulfoxide (DMSO) and potassium phosphate buffer, $50 \mathrm{mmol} \mathrm{L}^{-1}$ (pH 7.0). After incubation for $15 \mathrm{~min}$ at $37{ }^{\circ} \mathrm{C}$ the reaction was stopped by adding $2 \mathrm{~mL}$ of acetone, and the p-nitrophenol released was detected at $410 \mathrm{~nm}$ in a spectrophotometer (Gomes et al., 2011). One unit of activity was defined as the amount of enzyme that produces $1 \mu \mathrm{mol}$ of $\mathrm{p}$-nitrophenol per minute under the assay conditions.

\section{Statistical Analysis}

The results are presented on a mean and standard error basis, using Tukey's test $(\mathrm{p}<0.05)$ with the aid of the program Statistica ${ }^{\circledR} 7.0$.

\section{RESULTS AND DISCUSSION}

\section{Raw Materials Characterization}

TPOMW and WB have distinct characteristics that make each of them suitable for SSF applications (Table 1). Considering TPOMW characteristics like high water content $(\approx 75 \%)$ and aromatic compounds (expressed as total phenols), the use of such a raw material as the sole carbon source in SSF may be unfeasible. Unlike TPOMW, WB has a high nitrogen content that results in a low $\mathrm{C} / \mathrm{N}$ ratio. Relatively high nitrogen concentrations and lower $\mathrm{C} / \mathrm{N}$ ratios are better conditions for yeast growth, and typically required for lipase production by fungi (Lima et al., 2003; Cheirsilp and Louhasakul, 2013).

Table 1: Composition of TPOMW and WB.

\begin{tabular}{|l|r|r|}
\hline Parameters & TPOMW & \multicolumn{1}{|c|}{ WB $^{\mathbf{b}}$} \\
\hline Moisture (\%) & $75.31 \pm 0.14$ & $20.0 \pm 3.4^{1}$ \\
C (\%) & $51.66 \pm 1.54$ & $54.3 \pm 4.2^{\mathbf{1}}$ \\
N (\%) & $0.86 \pm 0.19$ & $2.6 \pm 0.3^{\mathbf{1}}$ \\
C/N & 60.06 & $17.3-24.9^{1}$ \\
Total phenols (mg/g) & $2.57 \pm 0.04$ & - \\
Protein (mg/g) & $0.30 \pm 0.03$ & $15.3 \pm 0.8^{\mathbf{2}}$ \\
Lipids (mg/g) & $102.46 \pm 0.04$ & $0.3 \pm 0.0^{\mathbf{1}}$ \\
Klason lignin (g/100g) & $58.16 \pm 0.41$ & $5.0^{\mathbf{3}}$ \\
\hline
\end{tabular}

${ }^{\text {a } A d o p t e d ~ f r o m ~ S a l g a d o ~ e t ~ a l ., ~} 2013$.

$\mathrm{b}^{1}$ Adopted from Jang et al., 2000.

$\mathrm{b}^{2}$ Adopted from Seguin et al., 2012.

$\mathrm{b}^{3}$ Adopted from Palmarola-Adrados et al., 2005. 
Thus, a mixture of both solids may represent a new strategy for application of non-useful waste such as TPOMW to obtain bioproducts with high added value.

\section{Solid Matrix Composition}

For the choice of the culture medium, both WB and TPOMW were tested as raw materials and the lipase production was evaluated after 24 hours of fermentation (Table 2). As expected, when used singly, TPOMW did not permit a suitable growth of $Y$. lipolytica (data not shown), which directly affected the lipase production by the yeast. This result is probably a consequence of the high amount of aromatic compounds, which are toxic for the cell. In addition, this residue has small particles that result in substrate stickiness, leading to poor water retention capacity. With a low capacity for moisture content, any high level can cause a porosity decrease, oxygen transfer limitation and poor growth (Moftah et al., 2012).

Table 2: Lipase activity in different solid matrix compositions.

\begin{tabular}{|l|r|}
\hline Culture medium & Activity (U/g) \\
\hline TPOMW & $0.79 \pm 0.15$ \\
WB & $14.08 \pm 0.78$ \\
TPOMW and WB (1:1) & $9.69 \pm 0.45$ \\
\hline
\end{tabular}

On the other hand, the combination between TPOMW and WB proved to be a good alternative for lipase production by the strain Y. lipolytica 50682 . When used as sole carbon source, WB also showed potential for microorganism growth and the lipase activity was slightly superior (around 30\%).

Considering that TPOMW is produced in large amounts and that a proper disposal of this material is not commonly realized, the utilization of viable management strategies is imperative (López-Piñeiro et al., 2008). The olive oil industry is very important in the Mediterranean, with a cultivated area of about 8.2 Mha and production of 0.8 ton of solid waste per ton of processed olives. Numerous investigations concerning the treatment of TPOMW have been made, but the solution of an adequate disposal has not yet been found (Federico et al., 2010).

To bypass the growth inhibition problem, the use of a second residue proved to be a good alternative. WB characteristics, such as high water retention capacity and high nitrogen level, ensured its potential for SSF (Javed et al., 2012). At the same time, the lipid content of TPOMW is higher and makes this residue interesting for lipolytic enzyme production. There are many researches in the SSF area showing the great potential of integrated use of wastes. Different residues can supply several nutrients for the fermentation, causing a synergic effect on enzyme production (Cordova et al., 1998; Babu and Rao, 2007; Santis-Navarro et al., 2011; Salgado et al., 2013). In the results reported herein, wastes combination showed potential for lipase production, since the limitation caused by TPOMW was apparently overcome, providing a new possibility for TPOMW utilization, adding value to the olive mill waste.

Relevant to this new strategy, some works deal with different materials, like Cordova et al. (1998) that increased the lipase activity produced by two species of Rhizomucor genus by using an equal mixture of olive oil cake and sugarcane bagasse. The authors first tested only sugarcane bagasse for lipase production and the maximal activity obtained was $4.99 \mathrm{U} / \mathrm{g}$. But when the olive oil cake was added to SSF, lipase production reached $79.60 \mathrm{U} / \mathrm{g}$. The authors believed that the olive oil cake had the appropriate precursors necessary for lipase production.

Sun and $\mathrm{Xu}$ (2008) evaluated various agro-products including rice, corn flour, wheat flour, barley, oat, wheat bran, rice bran, wheat husk and soybean powder for lipase production by $R$. chinensis. Among all residues tested, wheat bran and wheat flour gave the highest activity. Since wheat flour and wheat bran both favored lipase production, the authors decided to experiment different residue combinations, and after some tests the ratio $3 / 2(\mathrm{w} / \mathrm{w})$ of wheat flour and wheat bran was chosen as the base medium for subsequent experiments. Coradi et al. (2012) also perceived that the combination of two residues was the most suitable for lipase production by $T$. harzianum. The highest enzyme activity of $4.0 \mathrm{U} / \mathrm{g}$ was obtained after $96 \mathrm{~h}$ of fermentation, in a medium containing castor bean and sugarcane bagasse. When the authors used both residues singly, the activities decreased despite the same cultivation conditions. For them, more important for lipase production than lipid content and nitrogen concentration, is the interaction between these variables.

It is important to note that, until now, no process optimization was carried out, this being a preliminary experiment to demonstrate the viability of using a mixture of TPOMW and WB. Thus, lipase production in SSF using these raw materials has to be studied to increase its productivity.

\section{Lipase Production in SSF}

Since the mixed composition was chosen as the solid matrix for SSF, the influence of different proportions of TPOMW and WB on lipase production was evaluated. For this initial test, a $0.5 \%(\mathrm{w} / \mathrm{v})$ urea 
solution was used as nitrogen supplementation and for the adjustment of moisture content. A total of 10 $\mathrm{g}$ of solid matrix were used with the following waste quantities (TPOMW/WB): $1: 1 ; 1: 3$ and $3: 1$. The fermentations were carried out for 96 hours and the lipase production was evaluated daily.

As shown in Figure 1, lipase production was higher in the medium with equal proportions of each raw material, reaching $94 \mathrm{U} / \mathrm{g}$ of lipase activity after 24 hours of fermentation. The medium with a minimum of TPOMW also showed its best result in the first 24 hours of fermentation $(15.5 \mathrm{U} / \mathrm{g})$, different from the medium with maximum of TPOMW that had its best lipase production only after 72 hours of fermentation $(30 \mathrm{U} / \mathrm{g})$. This result demonstrates how lipase activity is affected by lipid-rich substrates; even with the presence of phenolic compounds that could inhibit fungal growth, the medium with $75 \%$ of TPOMW also produced an expressive lipase activity. Several extracellular elements that affect the expression of lipase are described in the literature, but the carbon source seems to be a critical one. These enzymes are usually produced in the presence of lipid, such as plant seed-oils (triacylglycerols), free fatty acids, surfactants, bile salts, and glycerol, that are included in the nutrient medium as inducers (Kebabci and Cihangir, 2012). Lip2, for example, is strongly affected by oleic acid, the end product of the hydrolysis of its preferred substrate (Fickers et al., 2011).

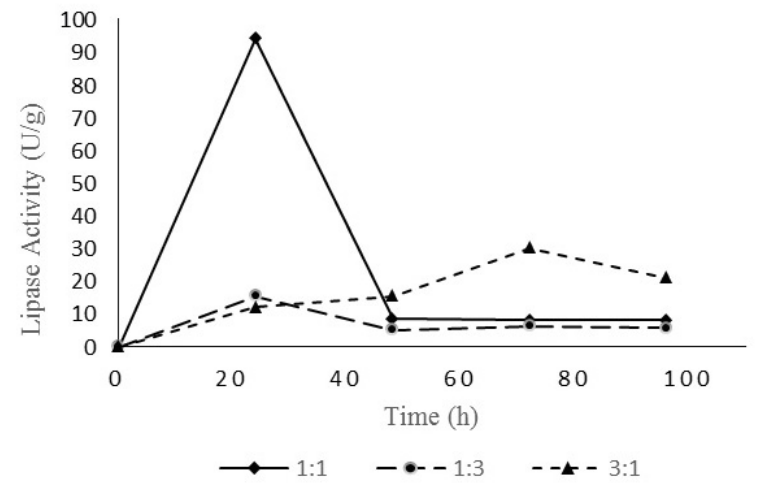

Figure 1: Lipase activity of three different raw materials ratios.

However, it is possible to observe a delay in lipase production, probably due to the high $\mathrm{C} / \mathrm{N}$ ratio. It is known that the lipase produced by yeasts usually stays internally bound to the cell wall and it is only secreted to the culture medium when the carbon source becomes scarce, i.e., in the transition to diauxie (when more than one substrate is used) or to the stationary phase. In a medium with a high $\mathrm{C} / \mathrm{N}$ ratio there is a surplus of carbon sources that can retard the lipase secretion (Pereira-Meireles et al., 2000). Similarly, a strain of Yarrowia lipolytica showed a delay in the transition between the two phases when an oleic acid rich medium was used. At the early stage of the culture when oleic acid was abundant, lipases remained cell-bonded, which were sufficient to support yeast growth. The enzymes were only released into the culture medium as the oleic acid concentrations decreased (Fickers et al., 2004).

\section{Effect of Nitrogen Source on Lipase Production}

The nitrogen source, organic or inorganic, also plays an important role in lipase production. For this reason, the effect of ammonium sulfate on lipase production was evaluated and compared to urea as nitrogen supplementation. The fermentations were performed for 96 hours with a ratio of 1:1 (TPOMW/ WB). Lipase activity and $\mathrm{pH}$ were evaluated daily.

Ammonium sulfate showed a different production profile when compared to urea. The presence of this mineral source not only increased lipase activity, but also kept levels rising throughout most of the fermentation process, reaching $486 \mathrm{U} / \mathrm{g}$ at the end of the process (Figure 2). Similar to previous experiments, urea supplementation promoted a positive effect on lipase production with a peak at 24 hours of fermentation. However, the maximal lipase activity was $145 \mathrm{U} / \mathrm{g}$ (Figure 2), almost three fold lower than that obtained with ammonium sulfate. Nitrogen compounds also modulate the synthesis of Lip2 and, according to several authors, organic sources are better for this purpose. While the presence of nitrogen compounds such as casein tryptone, urea and yeast extract usually yields significant lipase synthesis, the opposite occurs when a mineral source is used (PereiraMeireles et al., 1997; Fickers et al., 2004). Turki et al. (2009) studied the extracellular lipase production by Yarrowia lipolytica overproducing mutant under the effect of several organic nitrogen sources. They concluded that enzymatic hydrolyzed casein (tryptone and peptone) had a relevant stimulatory effect on lipase production, suggesting that the enhancement relies most probably on the presence of some specific bioactive peptides that act as lipase inducers. Urea is also reported as a better nitrogen supplementation than ammonium sulfate for lipase production by Yarrowia lipolytica. Usually, when this mineral nitrogen is used the lipase production is inhibited (Corzo and Revah, 1999; Imandi et al., 2010). 


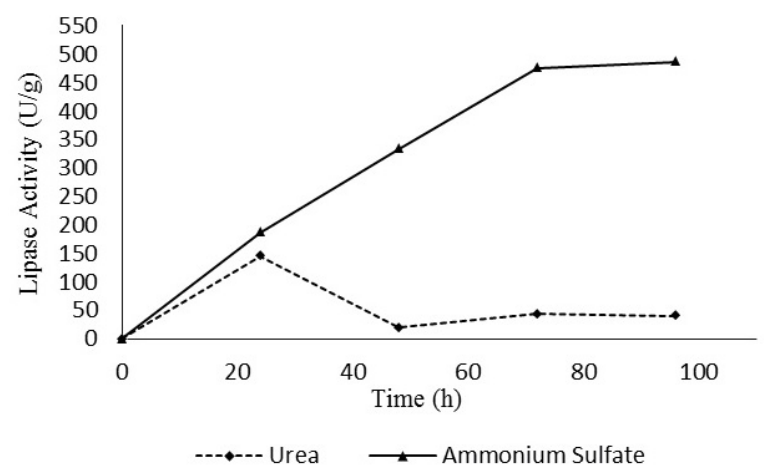

Figure 2: Influence of nitrogen supplementation on lipase activity.

Our results, in disagreement with other researchers, showed the great potential of ammonium sulfate for lipase production by the yeast $Y$. lipolytica. In some level, the conditions offered by the raw materials and ammonium sulfate allowed an improvement of the productivity (Figure 3 ). The fermentations with ammonium sulfate supplementation not only had higher lipase production than urea, but also presented higher productivity. In the first 24 hours, the productivity reached its best range with $7.8 \mathrm{U} / \mathrm{g} * \mathrm{~h}$, and after four days of the process only decreased about $35 \%$. This promising result confirms the potential of our experiments since the lipase productivity was higher than most of the productivities reported in the literature (Imandi et al., 2010; Moftah et al., 2012; Coradi et al., 2012; Vaseghi et al., 2013; Salgado et al., 2013), which is very important for an economically viable process. Although the organic nitrogen sources are generally cited for lipase production, the use of inorganic ones has been studied due to their low cost and to facilitate the subsequent stages of enzyme purification.

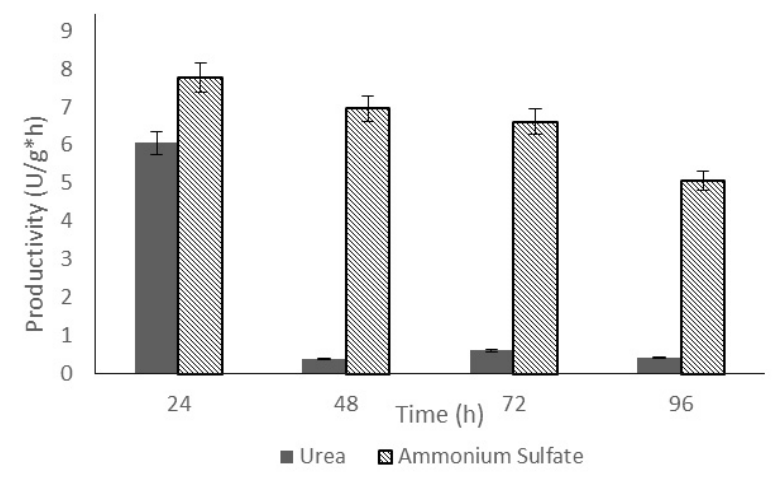

Figure 3: Influence of urea and ammonium sulfate on lipase productivity.

In recent research, the impact of $\mathrm{NH}_{4}^{+}$nitrogen source on lipase production by Pichia pastoris was investigated, and the results demonstrated the positive effect of this ion. Ammonium sulfate was added in order to provide the ammonium ion and keep it constant at three levels, $400 \mathrm{mmol} / \mathrm{L}, 440 \mathrm{mmol} / \mathrm{L}$ and $500 \mathrm{mmol} / \mathrm{L}$. The highest lipase activity was obtained at a concentration of $440 \mathrm{mmol}$ after 52 hours, with an increase of $71 \%$ considering the control system. The presence of $\mathrm{NH}_{4}{ }^{+}$in the broth also prevented protease production ( $\mathrm{Yu}$ et al., 2013), a fact that can explain the higher maintenance of lipase production all along the fermentation with this nitrogen source.

The use of ammonium sulfate showed a linear increase in lipase production with bath time that provided an almost constant productivity up to $72 \mathrm{~h}$ (Figure 3), meaning that no decrease in enzyme activity was observed. On the other hand, the use of urea showed a decreased in lipase activity after $24 \mathrm{~h}$, which led to a low productivity. These results permit one to plan the process strategy to obtain higher productivities.

Kebabci and Cihangir (2012) studied lipase production by three different $Y$. lipolytica strains, evaluating different nitrogen supplementation (proteosepeptone, peptone, yeast extract, casein, urea, ammonium sulfate, ammonium oxalate, ammonium nitrate and ammonium carbonate) with and without olive oil. The authors concluded that addition of ammonium compounds led to the best increase in lipase production. In their case, the combination between ammonium sulfate and olive oil permitted the best condition for enzyme production in an acid $\mathrm{pH}$ range.

In the study reported herein, the $\mathrm{pH}$ was also evaluated for both nitrogen sources. Similarly, the best $\mathrm{pH}$ for lipase production with ammonium sulfate varied in an acid range, between 5.5-5.9 (Figure 4B). When urea was used, the $\mathrm{pH}$ profile was different, ranging between 7.0-7.8 (Figure 4A). The optimal $\mathrm{pH}$ reported for Lip2 hydrolytic activity was found to be slightly acid, although it can vary depending on the substrates and the experimental conditions (Fickers et al., 2011). In addition, the optimum hydrolytic activity of lipases from $Y$. lipolytica is usually obtained between $\mathrm{pH} 6.0$ and 10.0, depending on the strain used (Brígida et al., 2013). According to Dominguez et al. (2003), low pH in the fermentation broth can be attributed to the release of fatty acids in the presence of lipase, which can explain the better productivity in acid $\mathrm{pH}$.

On the other hand, a $\mathrm{pH}$ increase during SSF fermentation can be attributed to the increase in the levels of protease that leads to release of amino acids from degraded proteins (Rigo et al., 2010). The yeast 
Y. lipolytica can produce large amounts of proteolytic enzymes; among them, alkaline protease (AEP) and acid protease (AXP) are the most common. Alkaline proteases, however, are the major protein secreted, reaching several grams per litre under optimized conditions (Nicaud et al., 2002). The secretion of this enzyme can occur in parallel to lipase and it is induced at neutral/basic $\mathrm{pH}$. Although in this work no proteolytic data was available, the $\mathrm{pH}$ verified in our experiments can give us some information about the fermentations. In addition, other work in the group using the same strain in SSF demonstrated that, up to $14 \mathrm{~h}$ of the process there is no detectable protease activity (data not shown).

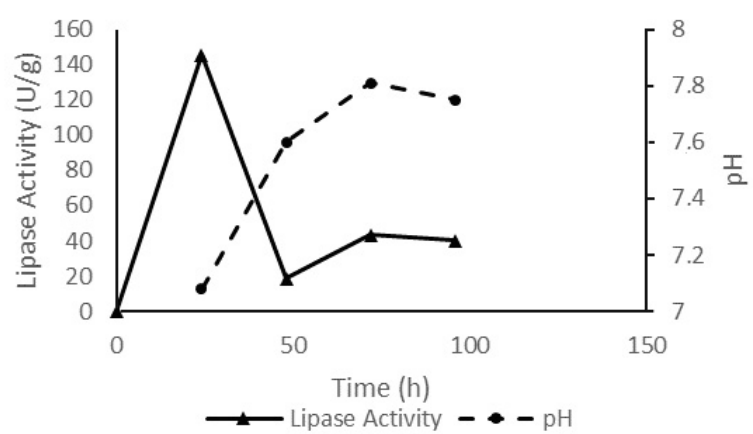

(A)

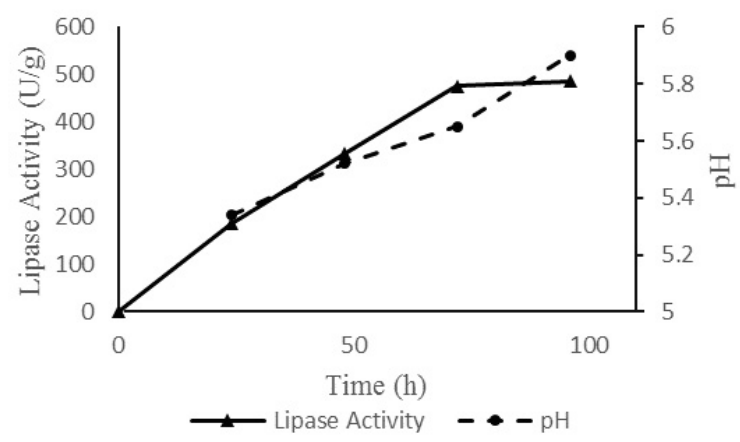

(B)

Figure 4: Comparison of lipase activity and $\mathrm{pH}$ in the medium with urea supplementation (A) and ammonium sulfate supplementation (B).

Nevertheless, Najjar et al. (2011) demonstrated that, independent of the culture medium, the lipase activity was always lost in the late stage of culture when the $\mathrm{pH}$ reached alkaline values, suggesting a proteolytic degradation by AEP. Similarly, our results show that, in the medium with neutral/ basic $\mathrm{pH}$, the lipase activity reached its lowest value. In the medium with urea, a greater $\mathrm{pH}$ increase $(\mathrm{pH} 7.0$ to $\mathrm{pH}$ 7.6) was followed by an expressive decrease in lipase production (Figure 4A). In the medium containing ammonium sulfate, that had higher lipase activity, the $\mathrm{pH}$ was not optimum for AEP (Figure 4B). Moreover, protease production is tightly controlled by a combination of environmental stimuli, which includes nutrient availability such as carbon, nitrogen, and sulfur starvation (Gonzalez-Lopez et al., 2002). The presence of nitrogen (ammonium ions, amino acids) and sulfur can have a repressive effect on AEP and AXP production (Young et al., 1996).

\section{CONCLUSIONS}

The yeast Yarrowia lipolytica IMUFRJ 50682 showed great potential for lipase production in solid state fermentation using agro-industrial residues. The raw materials TPOMW and WB had complementary effects, offering suitable conditions for SSF when used in equal proportions due to their characteristics concerning toxic compounds, moisture content and $\mathrm{C} / \mathrm{N}$ ratio. In addition, the supplementation with a mineral nitrogen source enhanced lipolytic activity, reaching the best result of $486 \mathrm{U} / \mathrm{g}$ after 96 hours. Ammonium sulfate improved lipase production and the productivity of the process, whereas urea had a less significant effect.

\section{ACKNOWLEDGEMENTS}

The authors kindly acknowledge the financial aid and research scholarships given by CAPES. Maria Alice Zarur Coelho thanks CNPq (Proc. 308890/ 2013-2).

\section{REFERENCES}

Almeida, A. F., Taulk-Tornisielo, S. M. and Carmona, E. C., Influence of carbon and nitrogen sources on lipase production by a newly isolated Candida viswanathii strain. Annals of Microbiology, 63, 1225-34 (2012).

Babu, I. S. and Rao, G. H., Lipase production by Yarrowia lipolytica NCIM 3589 in solid state fermentation using mixed substrate. Research Journal of Microbiology, 2, 469-74 (2007).

Barth, G. and Gaillardin, C., Physiology and genetics of the dimorphic fungus Yarrowia lipolytica. FEMS Microbiology Reviews, 19, 219-37 (1997).

Bora, L., Gohain, D. and Das, R., Recent advances in production and biotechnological applications of thermostable and alkaline bacterial lipases. Journal of Chemical Technology and Biotechnology, 88, 1959-70 (2013). 
Brígida, A. I. S., Amaral, P. F. F., Coelho, M. A. Z. and Gonçalves, L. R. B., Lipase from Yarrowia lipolytica: Production, characterization and application as an industrial biocatalyst. Journal of Molecular Catalysis, B, Enzymatic, 101, 148-58 (2013).

Cervantes-Chávez, J. A. and Ruiz-Herrera, J., The regulatory subunit of protein kinase A promotes hyphal growth and plays an essential role in Yarrowia lipolytica. FEMS Yeast Research, 7, 929-40 (2007).

Cheirsilp, B. and Louhasakul, Y., Industrial wastes as a promising renewable source for production of microbial lipid and direct transesterification of the lipid into biodiesel. Bioresource Technology, 142, 329-37 (2013).

Coelho, M. A. Z., Amaral, P. F. F. and Belo, I., Yarrowia lipolytica: An industrial workhorse. In: A. Méndes-Vilas, Editor. Current Research, Technology and Education. Topics in Applied Microbiology and Microbial Biotechnology. FORMATEX (2010).

Coradi, G. V., Visitação, V. L., Lima, E. A., Saito, L. Y. T., Palmieri, D. A., Takita, M. A., Oliva Neto, P., Lima, V. M. G., Comparing submerged and solidstate fermentation of agro-industrial residues for the production and characterization of lipase by Trichoderma harzianum. Annals of Microbiology, 63, 553-540 (2012).

Cordova, J., Nemmaoui, M., Isma1li-Alaoui, M., Morin, A., Roussos, S., Raimbault, M., Benjilali, B., Lipase production by solid state fermentation of olive cake and sugar cane bagasse. Journal of Molecular Catalysis B: Enzymatic, 5, 75-8 (1998).

Corzo, G. and Revah, S., Production and characteristics of the lipase from Yarrowia lipolytica 681. Bioresource Technology, 70, 173-80 (1999).

Darvishi, F., Microbial Biotechnology in Olive Oil Industry, Olive Oil - Constituents, Quality, Health Properties and Bioconversions. Dr. Dimitrios Boskou (Ed.), InTech (2012).

Demir, H. and Tar1, C., Valorization of wheat bran for the production of polygalacturonase in SSF of Aspergillus sojae. Ind. Crops Prod., 54, 302-9 (2014).

Domínguez, A., Costas, M., Longo, M. A. and Sanromán, A., A novel application of solid state culture: production of lipases by Yarrowia lipolytica. Biotechnology Letters, 25, 1225-9 (2003).

Federico, C, Sánchez-Peinado, M. M., Juárez-Jimenez, B., González-López, J., Pozo, C., Biological Treatment of Two-Phase Olive Mill Wastewater (TPOMW, alpeorujo): Polyhydroxyalkanoates
(PHAs) Production by Azotobacter Strains. J. Microbiol. Biotechnol., 20, 594-601 (2010).

Fickers, P., Nicaud, J. M., Gaillardin, C., Destain, J. and Thonart, P., Carbon and nitrogen sources modulate lipase production in the yeast Yarrowia lipolytica. Journal of Applied Microbiology, 96, 742-9 (2004).

Fickers, P., Marty, A. and Nicaud, J. M., The lipases from Yarrowia lipolytica: Genetics, production, regulation, biochemical characterization and biotechnological applications. Biotechnology Advances, 29, 632-44 (2011).

Gomes, N., Gonçalves, C., García-Román, M., Teixeira, J. A. and Belo, I., Optimization of a colorimetric assay for yeast lipase activity in complex systems. Analytical Methods, 3, 1008-13 (2011).

Gonzalez-Lopez, C. I., Szabo, R., Blanchin-Roland, S., Gaillardin, C., Genetic control of extracellular protease synthesis in the yeast Yarrowia lipolytica. Genetics, 160, 417-27 (2002).

Haegler, A. N. and Mendonça-Haegler, L. C., Yeast from marine and estuarine waters with different levels of pollution in the State of Rio de Janeiro, Brazil. Applied and Environmental Microbiology, 41, 173-178 (1981).

Hasan, F., Shah, A. A. and Hameed, A., Industrial applications of microbial lipases. Enzyme and Microbial Technology, 39, 235-51 (2006).

Imandi, S. B., Karanam, S. K. and Garapati, H. R., Optimization of process parameters for the production of lipase in solid state fermentation by Yarrowia lipolytica from niger seed oil cake (Guizotia Abyssinica). Journal of Microbial \& Biochemical Technology, 02, 028-33 (2010).

Jang, H., Lin, Y. and Yang, S., Polyunsaturated fatty acid production with Mortierella alpina by solid substrate fermentation. Botanical Bulletin-Academia Sinica Taipei, 41, 4-11 (2000).

Javed, M. M., Zahoor, S., Shafaat, S., Mehmooda, I., Gul, A., Rasheed, H., Bukhari, S. A. I., Aftab, M. N. and Haq, I., Wheat bran as a brown gold: $\mathrm{Nu}-$ tritious value and its biotechnological applications. African Journal of Microbiology Research, 6, 724-33 (2012).

Kebabç1, Ö., Cihangir, N., Comparison of three Yarrowia lipolytica strains for lipase production: NBRC 1658, IFO 1195, and a local strain. Turkish Journal of Biology, 36, 15-24 (2012).

Lama-Muñoz, A., Rodríguez-Gutiérrez, G., RubioSenent, F., Palacios-Díaz, R. and Fernández-Bolaños, J., A study of the precursors of the natural antioxidant phenol 3,4-dihydroxyphenylglycol in olive oil waste. Food Chemistry, 140, 154-60 (2013). 
Lima, V. M. G., Krieger, N., Sarquis, M. I. M., Mitchell, D. A., Ramos, L. P. and Fontana, J. D., Effect of nitrogen and carbon sources on lipase production by Penicillium aurantiogriseum. Food Technology and Biotechnology, 41, 105-10 (2003).

López-Piñeiro, A., Albarrán, A., Nunes, J. M. R., Barreto, C., Short and medium-term effects of two-phase olive mill waste application on olive grove production and soil properties under semiarid mediterranean conditions. Bioresour. Technol., 99, 7982-7 (2008).

Maes, C. and Delcour, J. A., Structural characterisation of water-extractable and water-unextractable arabinoxylans in wheat bran. Journal of Cereal Science, 35, 315-26 (2002).

Moftah, O. A. S., Grbavčić, S., Zuža, M., Luković, N., Bezbradica, D. and Knežević-Jugović, Z., Adding value to the oil cake as a waste from oil processing industry: Production of lipase and protease by Candida utilis in solid state fermentation. Applied Biochemistry and Biotechnology, 166, 348-64 (2012).

Muktadirul Bari Chowdhury, A. K. M., Akratos, C. S., Vayenas, D. V. and Pavlou, S., Olive mill waste composting: A review. International Biodeterioration and Biodegradation, 85, 108-19 (2013).

Najjar, A., Robert, S., Guérin C., Violet-Asther, M. and Carrière, F., Quantitative study of lipase secretion, extracellular lipolysis, and lipid storage in the yeast Yarrowia lipolytica grown in the presence of olive oil: Analogies with lipolysis in humans. Applied Microbiology and Biotechnology, 89, 1947-62 (2011).

Nicaud, J-M., Madzak, C., van den Broek, P., Gysler, C., Duboc, P., Niederberger, P., Gaillardin, C., Protein expression and secretion in the yeast Yarrowia lipolytica. FEMS Yeast Res., 2, 371-9 (2002).

Palmarola-Adrados, B., Choteborská P., Galbe, M. and Zacchi, G., Ethanol production from nonstarch carbohydrates of wheat bran. Bioresource Technology, 96, 843-50 (2005).

Papanikolaou, S. and Aggelis, G., Yarrowia lipolytica: A model microorganism used for the production of tailor-made lipids. European Journal of Lipid Science and Technology, 112, 639-54 (2010).

Pereira-Meireles, F. V., Rocha-Leão, M. H. M. and Sant'Anna, G. L. Jr. A., Stable lipase from Candida lipolytica: Cultivation conditions and crude enzyme characteristics. Applied Biochemistry and Biotechnology, 63, 73-85 (1997).

Pereira-Meireles, F. V., Rocha-leão, M. H. M. and Sant'Anna, G. L. Jr. A., Lipase location in Yarrowia lipolytica cells. Biotechnology Letters, 22, 71-5 (2000).
Pignède, G., Wang, H., Fudalej, F., Gaillardin, C., Seman, M., Nicaud, J.-M., Characterization of an Extracellular Lipase Encoded by LIP2 in Yarrowia lipolytica. Journal of Bacteriology, 182, 2802-10 (2000).

Reina, R., Liers, C., Ocampo, J. A., García-Romera, I. and Aranda, E., Solid state fermentation of olive mill residues by wood- and dung-dwelling Agaricomycetes: Effects on peroxidase production, biomass development and phenol phytotoxicity. Chemosphere, 93, 1406-12 (2013).

Rigo, E., Polloni, A. E., Remonatto, D., Arbter, F., Menoncin S., Oliveira, J. V., de Oliveira, D., Treichel, H., Kalil, S. J., Ninow, J. L., Di Luccio, M., Esterification activity of novel fungal and yeast lipases. Applied Biochemistry and Biotechnology, 162, 1881-8 (2010).

Romdhane, I. B., Fendri, A., Gargouri, Y., Gargouri, A. and Belghith, H., A novel thermoactive and alkaline lipase from Talaromyces thermophilus fungus for use in laundry detergents. Biochemical Engineering Journal, 53, 112-20 (2010).

Salgado, J. M., Abrunhosa, L., Venâncio, A., Domínguez, J. M. and Belo, I., Screening of winery and olive mill wastes for lignocellulolytic enzyme production from Aspergillus species by solid-state fermentation. Biomass Conversion and Biorefinery, 172, 1832-45 (2013).

Santis-Navarro, A., Gea, T., Barrena, R. and Sánchez, A., Production of lipases by solid state fermentation using vegetable oil-refining wastes. Bioresource Technology, 102, 10080-4 (2011).

Seguin, A., Marinkovic, S. and Estrine, B., New pretreatment of wheat straw and bran in hexadecanol for the combined production of emulsifying base, glucose and lignin material. Carbohydrate Polymers, 88:657-62 (2012).

Sun, S. Y. and $\mathrm{Xu}, \mathrm{Y}$., Solid-state fermentation for "whole-cell synthetic lipase" production from Rhizopus chinensis and identification of the functional enzyme. Process Biochemistry, 43, 219-24 (2008).

Thomas, L., Larroche, C. and Pandey, A., Current developments in solid-state fermentation. Biochemical Engineering Journal, 81, 146-61 (2013).

Turki, S., Kraeim, I. B., Weeckers, F., Thonart, P. and Kallel, H., Isolation of bioactive peptides from tryptone that modulate lipase production in Yarrowia lipolytica. Bioresource Technology, 100, 2724-31 (2009).

Turki, S., Ayed, A., Chalghoumi, N., Weekers, F., Thonart, P. and Kallel, H., An enhanced process for the production of a highly purified extracellular lipase in the non-conventional yeast Yarrowia 
lipolytica. Applied Biochemistry and Biotechnology, 160, 1371-85 (2010).

Vaseghi, Z., Najafpour, G. D., Mohseni, S., Mahjoub, S., Production of active lipase by Rhizopus oryzae from sugarcane bagasse: Solid state fermentation in a tray bioreactor. Int. J. Food Sci. Technol., 8, 283-9 (2013).

Veerabhadrappa, M. B., Shivakumar, S. B. and Devappa, S., Solid-state fermentation of Jatropha seed cake for optimization of lipase, protease and detoxification of anti-nutrients in Jatropha seed cake using Aspergillus versicolor CJS-98. Journal of Bioscience and Bioengineering, 117 (2), 1-7 (2013).
Yan, Y., Zhang, X. and Chen, D., Enhanced catalysis of Yarrowia lipolytica lipase LIP2 immobilized on macroporous resin and its application in enrichment of polyunsaturated fatty acids. Bioresource Technology, 131, 179-87 (2013).

Young, T. W., Wadeson, A., Glover, D. J., Quincey, R. V., Butlin, M. J., Kamei, E. A., The extracellular acid protease gene of Yarrowia lipolytica: Sequence and $\mathrm{pH}$-regulated transcription. Microbiology, 142, 2913-21 (1996).

Yu, X. W., Lu, X., Zhao, L. S. and Xu, Y., Impact of $\mathrm{NH}_{4}{ }^{+}$nitrogen source on the production of Rhizopus oryzae lipase in Pichia pastoris. Process Biochemistry, 48, 1462-8 (2013). 